- Original Paper •

\title{
Evidence of Specific MJO Phase Occurrence with Summertime California Central Valley Extreme Hot Weather
}

\author{
Yun-Young LEE$^{1}$ and Richard GROTJAHN*2 \\ ${ }^{1}$ Asia-Pacific Economic Cooperation Climate Center, Busan, 48058, South Korea \\ ${ }^{2}$ Department of Land, Air and Water Resources, University of California, CA 95616, USA
}

(Received 6 August 2018; revised 1 March 2019; accepted 6 March 2019)

\begin{abstract}
This study examines associations between California Central Valley (CCV) heat waves and the Madden Julian Oscillation (MJO). These heat waves have major economic impact. Our prior work showed that CCV heat waves are frequently preceded by convection over the tropical Indian and eastern Pacific oceans, in patterns identifiable with MJO phases. The main analysis method is lagged composites (formed after each MJO phase pair) of CCV synoptic station temperature, outgoing longwave radiation (OLR), and velocity potential (VP). Over the CCV, positive temperature anomalies occur only after the Indian Ocean (phases 2-3) or eastern Pacific Ocean (phases 8-1) convection (implied by OLR and VP fields). The largest fractions of CCV hot days occur in the two weeks after onset of those two phase pairs. OLR and VP composites have significant subsidence and convergence above divergence over the CCV during heat waves, and these structures are each part of larger patterns having significant areas over the Indian and Pacific Oceans. Prior studies showed that CCV heat waves can be roughly grouped into two clusters: Cluster 2 is preceded by a heat wave over northwestern North America, while Cluster 1 is not. OLR and VP composite analyses are applied separately to these two clusters. However, for Cluster 2, the subsidence and VP over the CCV are not significant, and the large-scale VP pattern has low correlation with the MJO lagged composite field. Therefore, the association between the MJO convection and subsequent CCV heat wave is more evident in Cluster 1 than Cluster 2.
\end{abstract}

Key words: MJO, heat wave, large-scale meteorological pattern, extratropical response, tropical convection

Citation: Lee, Y.-Y., and R. Grotjahn, 2019: Evidence of specific MJO phase occurrence with summertime California Central Valley extreme hot weather. Adv. Atmos. Sci., 36(6), 589-602, https://doi.org/10.1007/s00376-019-8167-1.

\section{Article Highlights:}

- Summertime California heat waves are preceded by MJO convection in the Indian Ocean and Southeast Asia and eastern tropical Pacific.

- In MJO phases 2-3 and 8-1, VP and OLR fields over California are part of a larger response extending into the subtropical eastern Pacific.

- Cluster 1 heat waves (that form in California) are more linked to MJO phases than Cluster 2 ones (from existing heat waves that expand over California).

\section{Introduction}

The California Central Valley (CCV) summer is characterized by occasional events having very high temperature. Extreme hot days, referred to here as heat waves, are not unusual in this area. These heat waves have temperatures higher than $38^{\circ} \mathrm{C}\left(100^{\circ} \mathrm{F}\right)$ for three or more days in a row. The CCV produces half of the nation's tree fruit and nut crops and includes extensive dairy production. Extremely high temperatures degrade the quality and quantity of agricultural production and in severe events cause extensive cow fatalities. The frequency and intensity of summer temperature extremes

\footnotetext{
* Corresponding author: Richard GROTJAHN

Email: grotjahn@ucdavis.edu
}

have large impacts on the regional economy of the CCV. For example, the CCV dairy industry had $\sim 1$ billion USD of economic losses from the heat waves that occurred in 2006. Therefore, understanding the mechanisms that lead to CCV hot weather is very important.

During boreal winter, extreme events have been linked to a blocking pattern and several climate modes, such as the Pacific-North American (PNA) pattern and North Atlantic Oscillation (Downton and Miller, 1993; Walsh et al., 2001; Wettstein and Mearns, 2002; Cellitti et al., 2006; Brown et al., 2008; Kenyon and Hegerl, 2008; Guirguis et al., 2011; Sillmann et al., 2011; Lee and Black, 2013; Loikith and Broccoli, 2014). There are substantial modulations of temperature extremes by El Niño-Southern Oscillation (ENSO) (Higgins et al., 2002; Meehl and Teng, 2007; Alexander et al., 2009; 
Lim and Schubert, 2011). It has also been shown that temperature extremes are accompanied by large displacements of air masses that create specific wave patterns-the socalled large-scale meteorological patterns (LSMPs) reviewed in Grotjahn et al. (2016) — which are distinct from the climate modes mentioned above. Regional-scale extreme heat in the CCV has been shown to be linked to LSMPs that are an equivalent barotropic, nearly stationary wave train (ridgetrough-ridge) across the North Pacific and western North America (Grotjahn and Faure, 2008; Grotjahn, 2011, 2013, 2016; Palipane and Grotjahn, 2018). Looking at the general features of LSMPs prior to the onset of heat waves is a good way to connect those heat waves with associated atmospheric phenomena and therefore begin to understand related mechanisms.

The Madden-Julian Oscillation (MJO) is the dominant mode of intraseasonal variability in the tropics (Madden and Julian, 1972, 1994; Zhang, 2005). However, its impacts are not limited to tropical latitudes and it has influences on the subtropical and extratropical flows in both hemispheres (Lau and Phillips, 1986; Kiladis and Weickmann, 1992; Higgins and Mo, 1997; Matthews et al., 2004). Tropical convection associated with the MJO generally propagates eastward through the Indian and Pacific Ocean basins with a periodicity of 40-50 days (Madden and Julian, 1972, 1994). Wheeler and Hendon (2004) developed a seasonally independent index to monitor the MJO. Based on their definitions, a phase number indicates longitudes of enhanced convection in the MJO life cycle: during phases 2-3 convection is enhanced over the Indian Ocean; in phases 4-5 over the Maritime Continent; in phases 6-7 over the western Pacific; and in phases 8-1 over the Western Hemisphere, as shown in outgoing longwave radiation (OLR) composites (Fig. 1). Purple boxes represent the active convective regions of the four phase-pair categories. Phase-pair 8-1 is called the eastern Pacific MJO phase in this study. Although MJO phase separation is less clear in summer than in winter (Wheeler and Hendon, 2004), the above classification is relevant enough to be applicable to summer MJO phases.

Enhanced sinking motion over western North America and just west-northwest of the CCV area is closely related with the onset of extreme CCV heat waves (Lee and Grotjahn, 2016). The sinking is strongest offshore but significant over the continent (Grotjahn, 2011). OLR composites in Fig. 1 show high values (implying clear skies from descent) over western North America and offshore during active MJO convection of phase-pair 2-3, but much less sinking motion during other phases. Therefore, the authors expect CCV area temperature extremes to be more likely after strong phasepair 2-3 of the MJO than after other phases. These results motivated this research into the MJO phase dependency of CCV hot weather.

Several researchers have shown MJO contributions to regional weather over diverse regions. The MJO strength and phase have influenced winter precipitation over East Asia (Jeong et al., 2008) and in North America and Canada (Lin et al., 2010; Zhou et al., 2012), and summer precipitation in
Australia (Wheeler et al., 2009). The MJO phases also influence winter surface temperatures over East Asia (Jeong et al., 2005) and in North America (Lin et al., 2009; Zhou et al., 2012; Schreck et al., 2013). Schreck et al. (2013) revealed that strong MJO contributes to eastern North America temperatures notably only when a specific PNA-like structure is present. Moon et al. (2011) showed that MJO influence on the temperature of the Canadian and northwestern United States coasts is dependent on ENSO phase. Specifically, during MJO phase 3, those areas experience cold weather during La Niña but warm weather during El Niño. Under MJO phase 7 , those areas experience warm and humid weather during El Niño.

The MJO may influence the occurrence of extreme weather. Hong and Li (2009) showed that the extreme cold anomaly over Southeast Asia in February 2008 occurred in association with the Maritime Continent MJO phase accompanying a mature-phase La Niña. Jones et al. (2011) demonstrated that the forecast skill for extreme precipitation over the contiguous United States becomes higher with active and enhanced MJO convection during phases 1 and 8. Matsueda and Takaya (2015) demonstrated the global influence of the MJO on extreme warm and cold conditions. However, most prior studies dealing with MJO influence on weather extremes emphasize the winter season. The MJO's association with summer-season weather extremes has not yet been well explored, to the best of our knowledge. This study examines summer-season hot weather in the CCV in association with MJO phases. Section 2 outlines the data and methods used. Section 3 examines which large-scale pattern of tropical convection in specific MJO phases is preferable for occurrence of $\mathrm{CCV}$ hot weather. Section 4 presents differences in the MJO's association with CCV heat waves sorted by the two types of CCV heat waves. Lastly, section 5 summarizes the results.

\section{Data and methods}

This study considers the boreal summer season as extending from June through September (122 days) and the time period from 1979 to 2010 (32 years). During this period, $24 \mathrm{CCV}$ summer heat wave events are isolated from the daily maximum near-surface temperature time series at 15 NCDC stations covering the whole CCV area. The criteria for identifying heat waves are detailed in Lee and Grotjahn (2016). Briefly, the criteria are that a majority of the CCV stations must have a maximum temperature within the top $5 \%$ for each station, simultaneously for at least three consecutive days. Two temperature extreme metrics are defined to measure the heat wave severity. One metric is the average of normalized temperature anomalies within specified days after MJO phase pairs. Even within the CCV, how extreme one degree of temperature anomaly is varies a lot among stations. Therefore, temperature anomalies are first normalized by the long-term daily mean standard deviation for each station to make all station values intercomparable. The other 
(a) $2-3$

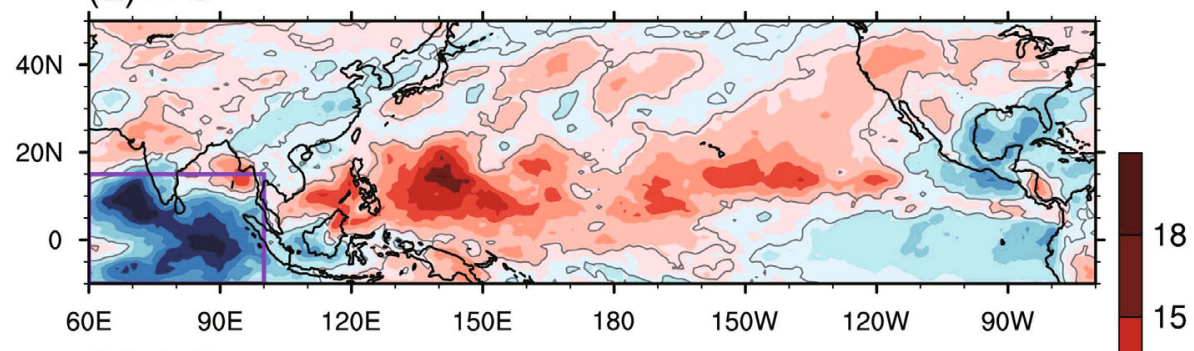

(b) $4-5$

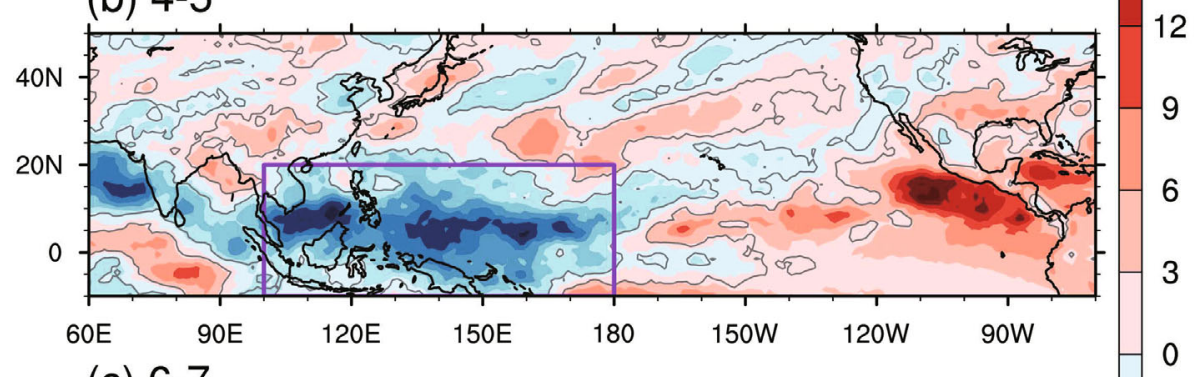

(c) 6-7

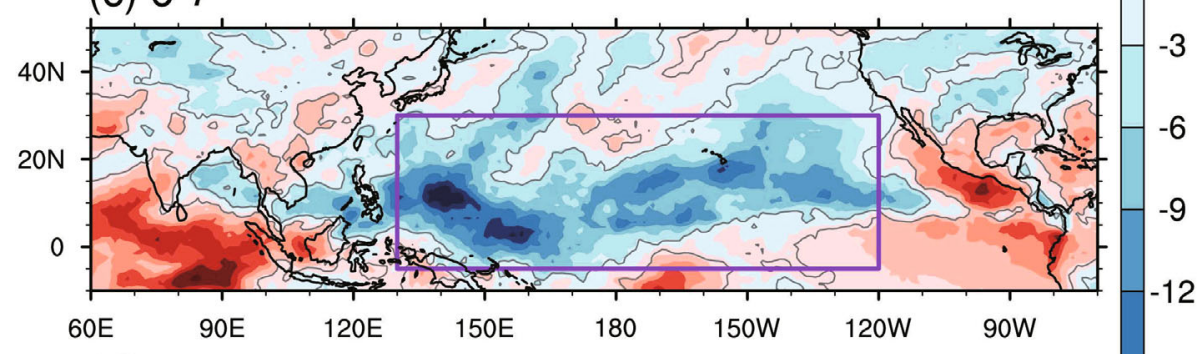

(d) 8-1

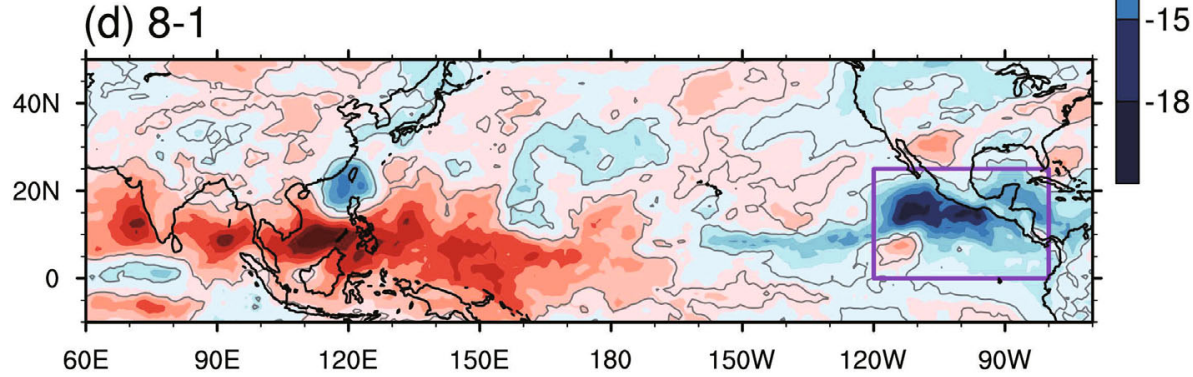

Fig. 1. OLR anomaly composites from onset dates of MJO events for four MJO phase pairs during summer 1979-2010. An MJO event must last at least three days, have RMM $\geqslant 1$, and be separated by $\geqslant 10$ days from another event. The units for the shading are $\mathrm{W} \mathrm{m}^{-2}$. Areas enclosed with grey contours are significant at the $95 \%$ confidence level according to the two-tailed Student's $t$-test. Purple boxes show areas of larger OLR magnitude for each MJO phase pair.

metric is the number of days (NODs) within the total number of 5\% hottest days that also occurs in each specified period after each MJO event; these NOD values are then divided by the total number of days to define the occurrence fractions (chance) of hot days.

The MJO phase is based on the Real-time Multivariate MJO (RMM) index (Wheeler and Hendon, 2004) obtained from the Australian Bureau of Meteorology data server (http://www3.bom.gov.au/twpice/forecast_trial/mjo/20050201 /RMM1RMM2.74toRealtime.txt.1107263700). Only active MJO days are considered here, and defined as those days when the RMM index has amplitude greater than or equal to one. This study simplifies the interpretation of the MJO relationships to CCV hot weather by emphasizing four zonal locations of tropical convection: the Indian Ocean, Maritime Continent, western-central Pacific, and eastern Pacific. This emphasis is accomplished by pairing two consecutive MJO phases (2-3, 4-5, 6-7, and 8-1) in all analyses here. To isolate sufficiently strong and discrete signals, MJO events are identified using three criteria when: (i) the RMM index phase persists for at least three days with amplitude of one or larger; (ii) the interval between two events is 10 days or longer; and (iii) both start and end dates of events are within the summer season from June through September. This process isolates 57, 64, 52, and 59 events for MJO phase pairs 2-3, 4-5, 6-7, and $8-1$, respectively. MJO Ll event composites clearly dis- 
play the typical zonal locations of active convection during individual MJO phase pairs (Fig. 1).

The characteristics of MJO phase-dependent convective motion are analyzed using daily mean OLR in $1^{\circ}$ latitude $\times 1^{\circ}$ longitude grid intervals. The OLR data are from HIRS radiance observations onboard NOAA's TIROS-N series and EUMETSAT's MetOp polar orbiting satellites (Lee et al., 2007). The data are available online at https://climatedataguide.ucar. edu/climate-data/outgoing-longwave-radiation-olr-hirs.

The upper- and lower-tropospheric divergence/convergence conditions associated with MJO convection are examined by analyzing the velocity potential (VP) derived from ERAInterim data (Dee et al., 2011). These data have a 6-h temporal resolution and $1^{\circ}$ longitude $\times 1^{\circ}$ latitude spatial resolution, and were obtained from http://apps.ecmwf.int/datasets/data/ interim-full-daily/.

This study emphasizes composites of OLR and VP anomaly fields from selected lag days after the onset date of MJO events to understand MJO-related atmospheric conditions in the CCV environs. Those results are compared with composite fields made during CCV heat wave events. For quantitative comparison, pattern correlation analysis is applied over a large horizontal domain covering the Indian Ocean and Pacific Ocean from the tropics to extratropics $\left(10^{\circ} \mathrm{S}-50^{\circ} \mathrm{N}, 60^{\circ} \mathrm{E}-90^{\circ} \mathrm{W}\right)$ in order to capture locations important in different MJO phases. Prior work (Lee and Grotjahn, 2016) found two different evolutions of the large-scale wind, mass, and temperature fields prior to the onset of $\mathrm{CCV}$ heat waves. Since our working hypothesis is that MJO phases preceding the onset of CCV heat waves may impact the properties of those heat waves, then our composite and pattern correlation analyses are sorted on the basis of these two distinct heat wave types or clusters.

\section{MJO phase dependency of CCV extreme hot weather occurrence}

\subsection{Tropical convection leading up to CCV hot weather}

Some properties of the weather and climate in the extratropics seem to lag properties of the MJO (Jin and Hoskins, 1995; Mori and Watanabe, 2008; Lin and Brunet, 2009; Lin et al., 2009, 2010; Schreck et al., 2013). Looking at OLR over a wide swath of the tropics and subtropics before the onset of $\mathrm{CCV}$ heat wave events gives hints at possible links between the tropics and the CCV.

Negative areas of OLR imply anomalously cold temperatures of cloud tops, and in the tropics the low temperatures are interpreted as arising from higher cloud tops associated with stronger moist convection. Hence, enhanced convection and negative OLR will be used interchangeably in this article for convenience. Similarly, positive OLR anomalies are associated with lower cloud tops or less cloudiness than average. Hence, positive OLR and enhanced subsidence will be used interchangeably. Figure 2 a shows the composite of OLR anomalies for 13 days prior to $24 \mathrm{CCV}$ heat wave events. In daily composites, the Indian Ocean and tropical eastern Pa- cific have anomalously strong convective anomalies out to 13 days before days of hotter CCV temperatures (not shown). In Fig. 2a, the tropical Indian Ocean has strong convection and it seems most closely related with phases 2-3 of MJO activity. The western-central Pacific has notable subsidence, opposite to MJO phases 6-7. Central America and Mexico have relatively weak but significant convection to the south of $10^{\circ} \mathrm{N}$ (related to MJO phase-pair 8-1).

The association between phase 2-3 MJO events and CCV extreme hot days is reinforced by another metric, shown in Fig. 2b. This metric first counts the number of days assigned to each of the four MJO phase pairs when either member of the pair has large amplitude $(\mathrm{RMM} \geqslant 1)$ during the 13 days leading up to the onset of extreme $\mathrm{CCV}$ heat wave events. Then, it is divided by the total number of days for 24 events $(13 \times 24$ days $)$ and the resultant active MJO days fraction is plotted as dark bars. Active-phase-pair 8-1 days occupy nearly $30 \%$ of the total number of days leading up to heat waves, while active-phase 4-5 days occupy less than $5 \%$. Since the number of days each phase is "active" varies, the fraction of all the summer days is also plotted (white bars). During 32 summer seasons, the fraction of active MJO phase days is rather similar and around $15 \%$ for each phase pair. Clearly, the fraction of days leading up to heat waves for phase-pair 8-1 is almost double the fraction of all summer days, and this indicates that the eastern Pacific convection is strongly associated with CCV hot weather. The fraction of days in phase-pair 2-3 is also slightly increased before heat wave onset. The other phases are less likely to occur before $\mathrm{CCV}$ heat waves than to a summer day on average.

The significant OLR convection and frequent MJO fraction shown in Fig. 2 may imply that, in terms of $\mathrm{CCV}$ heat waves, a link to tropical convection is relevant and the association may vary with the geographical locations of MJO convection. As a next step, this study examines CCV station temperature variation after each of the four different phase pairs in order to estimate when temperature changes appear related to a preceding MJO phase. In Fig. $3 \mathrm{a}$, the $15 \mathrm{CCV}$ stations' averaged normalized temperature anomalies (T_norm) are plotted at individual lag days after each indicated MJO phase-pair onset. For phase-pair 8-1, CCV temperature peaks at lag-day 12 but decreases gradually until dropping below zero after lag-day 16. Phase-pair 2-3 time series have a relatively sharp peak at lag-day 15 with slightly less T_norm compared to phase pair 8-1. For phase pair 4-5, CCV temperature anomaly stays under zero over all lag days. For phase pair 6-7, temperature starts negative crossing over zero after 15 days' lag.

Figure $3 \mathrm{~b}$ compares counts of extreme hot days averaged over the $15 \mathrm{CCV}$ stations at different lags for the four MJO phase pairs. Extreme hot days are identified when the T_norm on the date are among the 5\% hottest dates from all summer season days. The fraction of hot days is the largest during 7 to 14 days after the onset of phase-pair 8-1. It is relatively high during 14 to 16 days for phase-pair 2-3. Generally, phasepairs 4-5 and 6-7 have a comparatively small fraction through all lag days. The longer lag for phase-pair 2-3 than for phase- 


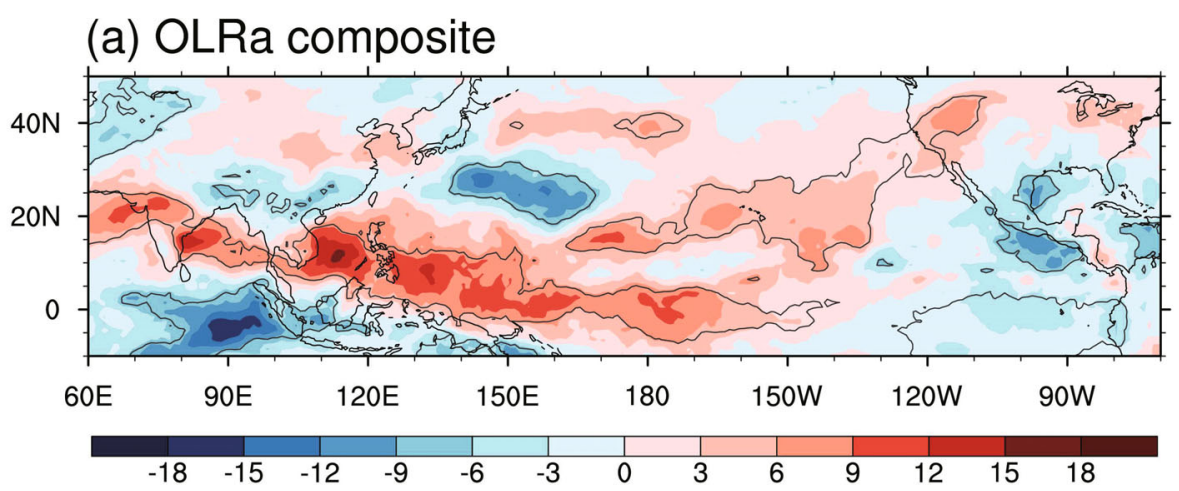

(b) MJO (amp>1) fraction

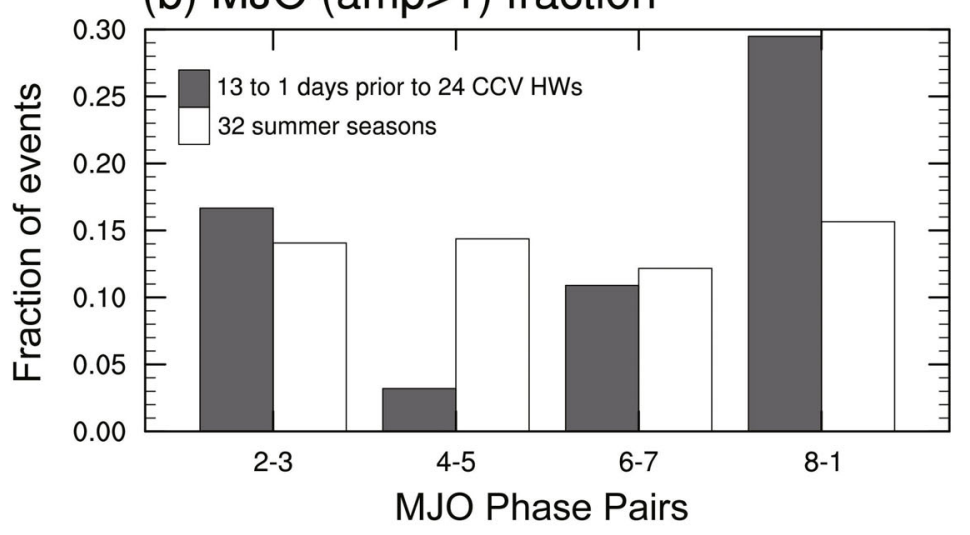

Fig. 2. (a) OLR anomaly composite during the 13 days prior to the onset of $24 \mathrm{CCV}$ heat wave events. The units for the shading are $\mathrm{W} \mathrm{m}^{-2}$. Areas enclosed with grey contours are significant at the 95\% confidence level according to the two-tailed Student's $t$-test. (b) Fraction of active MJO days with RMM amplitde $\geqslant 1$ for each of four phase pairs out of (dark grey) 13 days prior to all 24 heat wave onset dates and among (light grey) all 32 seasons of summer days.

pair 8-1 is perhaps unsurprising since the convection location of phase-pair 8-1 is much closer to the CCV than the location of phase-pair 2-3 convection. This shorter-distance argument is based in part on the assumption that some "signal" from the convection could propagate at a roughly similar rate in the different directions needed to reach the CCV. However, this shorter-distance argument breaks down when considering phase-pair 6-7 has its highest fractions after those of phase-pair 2-3. Also, the highest fraction for phase-pair 2-3 is at zero lag. Based on the results of Figs. $3 a$ and $b$, a timeframe of 4 to 16 lag days after MJO events is selected as a consistent timeframe over which the MJO phases are associated with $\mathrm{CCV}$ heat waves. Beyond this time lag the signal assigned to a particular MJO phase pair may actually be associated with an earlier or later phase pair.

Normalized temperature anomalies and hot-day fractions are averaged over 4 to 16 days after the onset of MJO events and displayed in Figs. $3 \mathrm{c}$ and d. Temperature anomalies are positive for phase-pairs 2-3 and 8-1 but negative for phasepairs 4-5 and 6-7. The fraction of hot days for phase-pair 8-1 is much larger than the other three phase pairs. Both temperature metrics have largest values in phase-pair 8-1 and secondlargest values in phase-pair 2-3. Thus, it is hypothesized that phase-pair 8-1 MJO (eastern Pacific convection) and phasepair 2-3 MJO (Indian Ocean convection) have higher association with subsequent $\mathrm{CCV}$ extreme hot days with larger frequency and strong amplitude than other phase pairs.

\subsection{MJO-related LSMPs favorable for CCV hot weather: $O L R$ and VP}

This section examines the link between CCV hot weather and MJO phase by focusing on the broader extratropical large-scale circulation patterns of OLR and VP following each phase pair of strong MJO events. The composites of each MJO phase pair for 4-16 days after the onset of active MJO events are compared to composites during heat wave events. Similarities in corresponding patterns between figures and the LSMPs in this section connect MJO occurrence and $\mathrm{CCV}$ weather.

Figures $4 \mathrm{a}-\mathrm{d}$ display the OLR anomaly composite of 4 to 16 days after the onset of MJO events for four phase pairs. Due to the lag in time, OLR patterns are displaced not only eastward but also northward compared to the active-day MJO composites centered on purple boxes (Fig. 1). Both negative and positive OLR (convection and subsidence) over the Indian Ocean to western Pacific region have a northwest to 
(a) Mean T norm

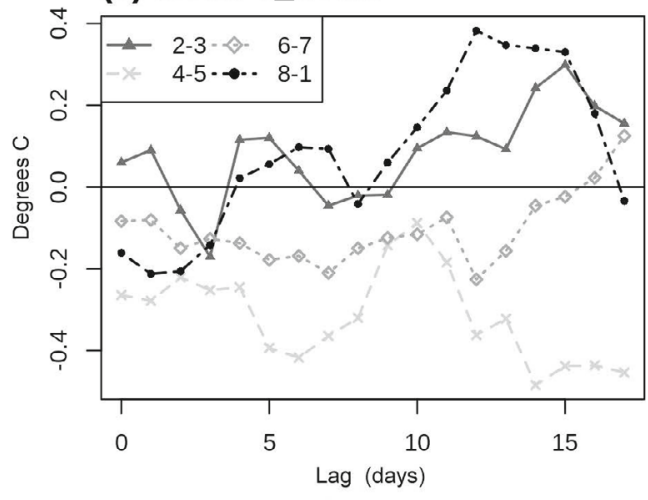

(c) Mean T_norm [4-16days]

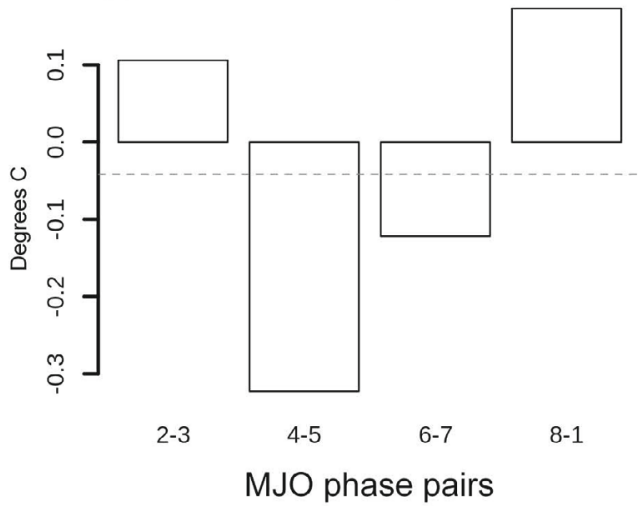

(b) Fraction of hot days

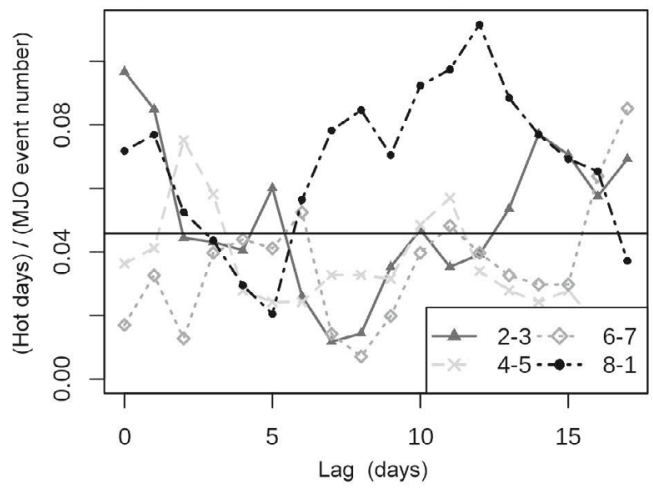

(d) Fraction of hot days [4-16days]

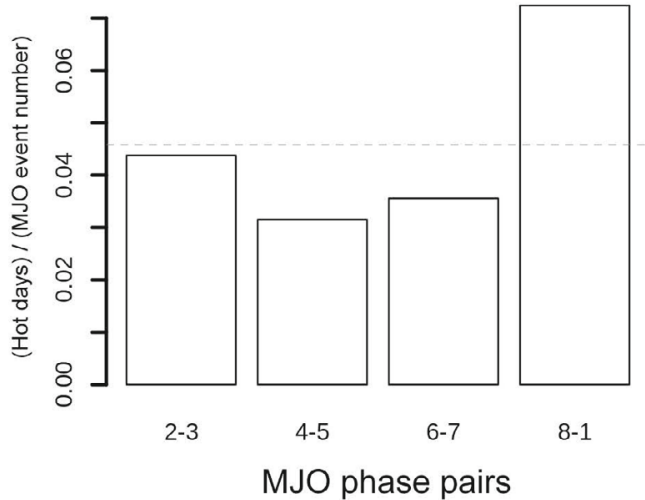

Fig. 3. Temporal evolution of (a) mean normalized temperature anomalies and (b) fraction of hot days averaged over $15 \mathrm{CCV}$ stations after the onset of MJO events during four phase pairs. Lag-day 1 is the day following the onset date of each individual MJO event. The average of (a) and (b) for 4-16 lag days is shown in (c) and (d). The horizontal dashed line denotes the average of four phase pairs in (c) and (d).

southeast elongation. The shift and shape of the OLR signal makes sense because northward propagation around Southeast Asia is a primary feature of the summertime MJO (Kiladis et al., 2014; Wang et al., 2018). After MJO phase-pair $8-1$, the main convective signal still remains inside the purple box (the tropical eastern Pacific). Outside the tropics, there are significant large positive OLR values over most of the western United States only after the 2-3 and 8-1 phase pairs. Negative OLR is significant over western North America after the 4-5 and 6-7 phase pairs. The average OLR anomaly over an area is a proxy measure of local rising or sinking of air parcels. The green box area average of OLR (Fig. 4e) clearly shows that subsidence (ascending motion) of air in the $\mathrm{CCV}$ can be enhanced during MJO convection over the Indian or eastern Pacific Oceans (Maritime Continent or western Pacific). Robustness of the CCV subsidence signal is also estimated by the "sign fraction", which measures the anomaly sign consistency between composite members by counting the number of events with positive anomaly values, subtracting the number of events with negative values at that point, and then dividing it by the total number of events at each grid point - a procedure similar to normalized "sign counts" used by Lee and Grotjahn (2016). A sign fraction of -1.0 indicates all events have a negative anomaly at that grid point, while $+1 / 3$ indicates two thirds of all events have a positive OLR anomaly. The subsidence over the CCV after both the 2-3 and 8-1 phase pairs is consistent by exceeding the $1 / 3$ signfraction level [Fig. S1 in the Electronic Supplementary Material (ESM)]. However, the enhanced negative OLR anomaly over the CCV after the 4-5 and 6-7 phase pairs is not consistent at that sign-fraction level.

Worthy of additional discussion are the Central America and tropical eastern Pacific convective anomalies combined with strong subsidence anomalies over western North America. This pattern looks partly consistent with the vertical velocity pattern shown by Hoskins et al. (1999) in their Fig. 3; their figure shows the pattern on day 12 from a primitive equation model simulation forced by heating over the so-called American monsoon region $\left(0^{\circ}-60^{\circ} \mathrm{N}, 110^{\circ}-\right.$ $\left.40^{\circ} \mathrm{W}\right)$. It was speculated that American monsoon convection amplifies subtropical North Pacific sea level pressure anticyclones through enhanced descent balanced by enhanced northerly winds on the eastern flank of those anticyclones (Hoskins, 1996; Hoskins et al., 1999). However, later work (Grotjahn and Osman, 2007) found observational evidence that the stronger Central American precipitation occurs af- 
(a) 2-3

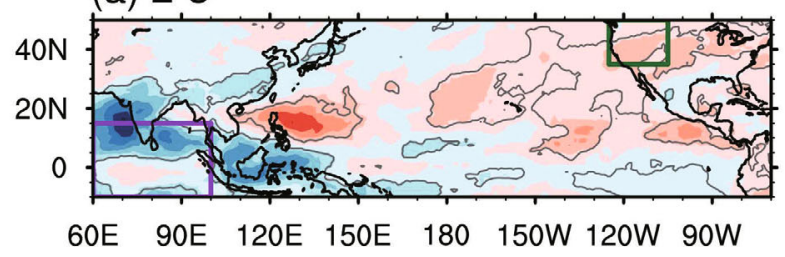

(b) $4-5$

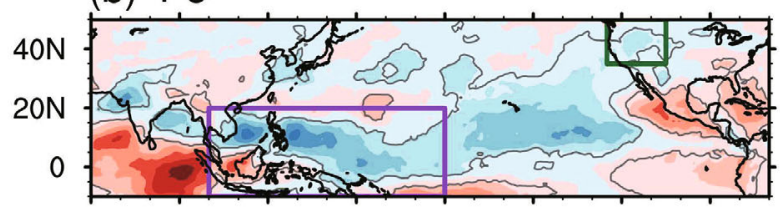

60E 90E 120E 150E 180 150W 120W 90W

(c) 6-7

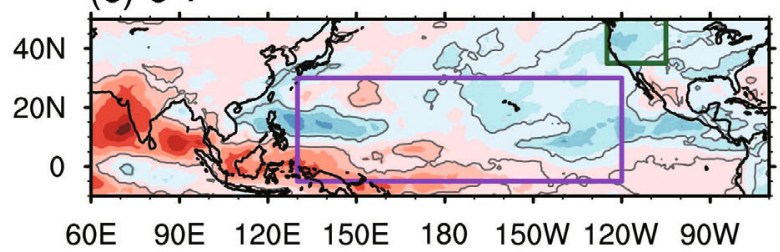

(d) 8-1

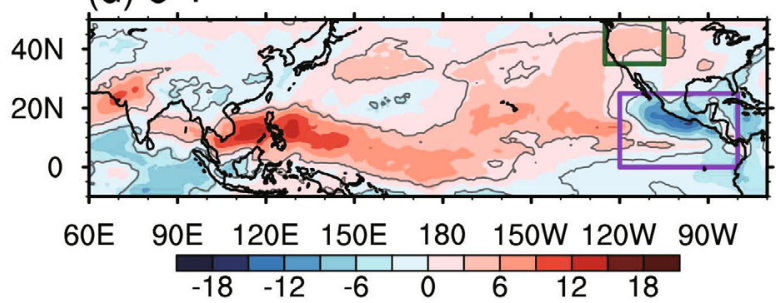

(e) Green box average

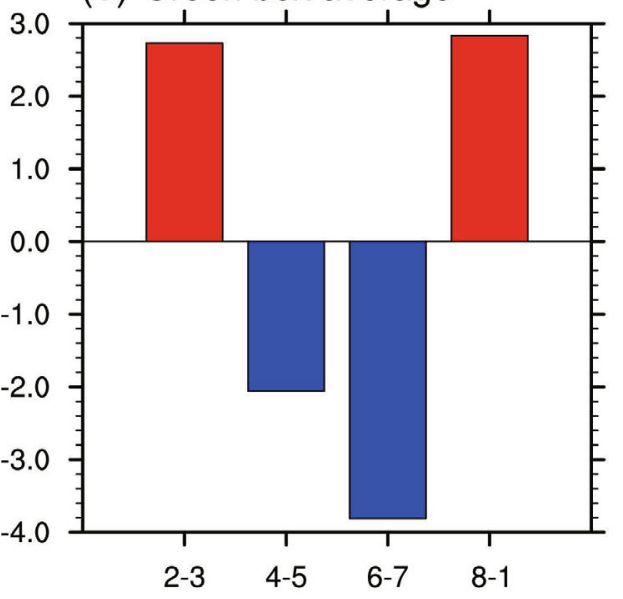

MJO phase pairs

Fig. 4. (a-d) OLR anomaly composites of 4-16 days after all MJO events' onset dates and (e) area-averaged OLR anomalies over the green boxed area for each of four phase pairs. Areas enclosed with grey contours in (a-d) are significant at the $95 \%$ confidence level according to the two-tailed Student's $t$-test. Purple boxes show areas of larger OLR magnitude in corresponding phase pairs (shown in Fig. 1). The green box shows an area of larger OLR magnitude near the $\operatorname{CCV}\left(35^{\circ}-50^{\circ} \mathrm{N}, 125^{\circ}-105^{\circ} \mathrm{W}\right)$.

ter (not before) the stronger subtropical high. Furthermore, there is a theoretical basis for enhanced eastern Pacific and Central American convection to lead to subsidence to the north-northwest found in the Matsuno-Gill models (Matsuno, 1966; Gill, 1980). Although our study emphasizes extremes and not the summertime mean state, a Rossby wave Matsuno-Gill response is also applicable to CCV temperature extremes after specific phases of MJO convection.

The 8-1 MJO phase pair is followed by significant abovenormal convection over the equatorial eastern Pacific and Central America northward to $25^{\circ} \mathrm{N}$ (Fig. 4d). Further north, over western America (green box), the OLR is significant and positive; prior works (Gershunov et al., 2009; Grotjahn, 2011) found an anticyclone centered over the United States Great Basin and Rocky Mountains. An anticyclone in this region can be generated by the Matsuno-Gill model. This enhanced inland anticyclone sets up a sea level pressure gradient to oppose a sea breeze that would otherwise cool the CCV (Grotjahn, 2011). Affiliated with that anticyclone produced by the Matsuno-Gill model and linked to western Ameri- can hot weather, corresponding OLR maxima are seen in the composite for MJO phase-pair 8-1.

The Laplacian of VP measures the strength of divergence and convergence at a specific atmospheric level. Being related to divergence via the Laplacian, the VP field is much smoother spatially than the divergence field, and that is why it is used here to identify very-large-scale structures associated with $\mathrm{CCV}$ heat waves and MJO phases. A positive relative maximum in VP broadly indicates convergence; a negative VP minimum implies divergence. Therefore, VP fields also imply vertical motion. Between convergence aloft and divergence below, air parcels sink and their sensible temperature increases adiabatically. It is well known that the subsidence inversion is enhanced during $\mathrm{CCV}$ heat waves and plays a key role, along with suppression of the sea breeze, in heat wave formation (Grotjahn, 2011).

Upper-level convergence over lower-level divergence occurs for regional sinking motion; therefore, this condition is expected near the CCV during heat wave events. To illuminate this structure, VP fields are analyzed near the CCV 
(a) $200 \mathrm{hPa}$

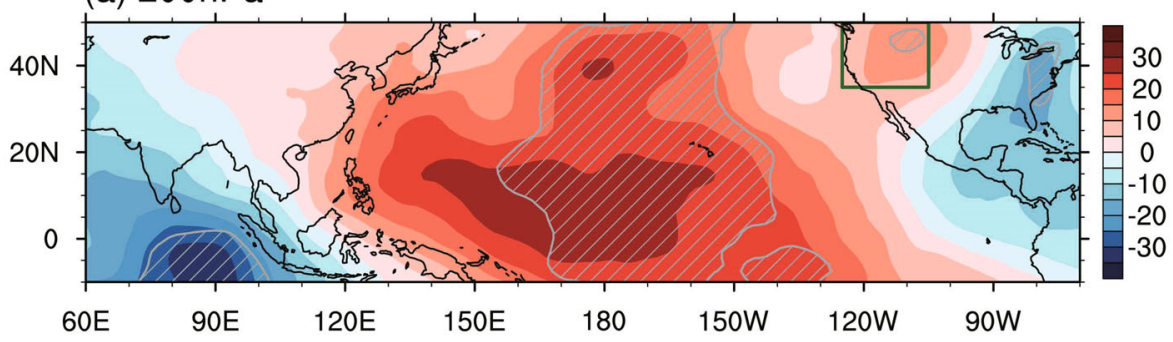

(b) $850 \mathrm{hPa}$

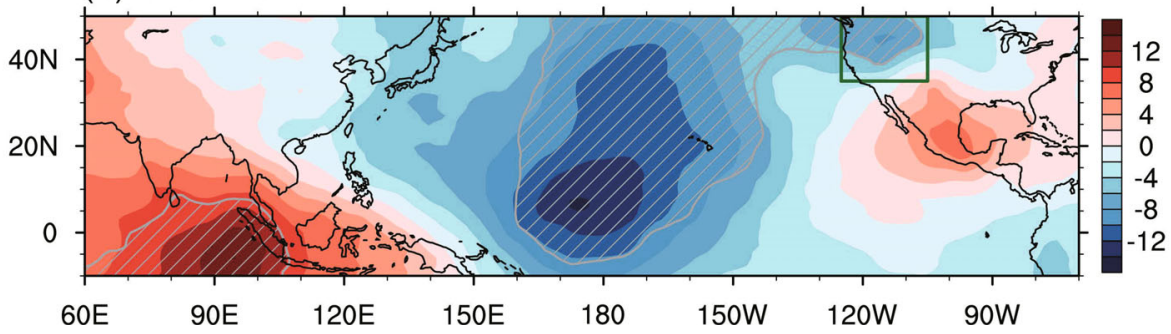

Fig. 5. VP anomaly composites from all $24 \mathrm{CCV}$ heat wave events over the first three days from heat wave onset for (a) $200 \mathrm{hPa}$ and (b) $850 \mathrm{hPa}$. The units for the shading are $10^{5} \mathrm{~m}^{2} \mathrm{~s}^{-1}$ Hatched areas enclosed with contours are significant at the $95 \%$ confidence level according to the two-tailed Student's $t$-test.

when heat waves develop. Figure 5 shows composites of $\mathrm{VP}$ anomalies for $24 \mathrm{CCV}$ heat wave events for the first three days from heat wave onset at both upper $(200 \mathrm{hPa})$ and lower $(850 \mathrm{hPa})$ tropospheric levels. Since the pressure velocity $(\mathrm{d} P / \mathrm{d} t)$ is much smaller at the ground than at its mid-tropospheric peak, upper- and lower-tropospheric VP anomaly fields generally have opposite sign where the VP magnitude is appreciable. This sign reversal with height is generally confirmed in most of the VP composite fields. Near the CCV (green box), a local maximum aloft and local minimum below are observed as expected, and the action center is east of the CCV. However, the sign reversal with elevation is less clear in the eastern United States; the upper-level VP negative activity center in the eastern United States does not overlie a strongly positive area. However, near southern Mexico and Central America, negative VP overlies positive VP in the lower level with similar gradient off the west coast of these lands. Outside North America, the upper-tropospheric VP anomaly shows clear zonal asymmetry: divergence over the tropical eastern Indian Ocean and convergence over the central Pacific (the latter extending into the extratropics); this pattern is reversed in the lower troposphere.

To investigate the delayed impact by the MJO phase on the formation of a convergence-over-divergence vertical structure, VP fields are analyzed from anomaly composites averaged over 4 to 16 days after the onset of each MJO pair (Fig. 6). The horizontal pattern of VP is quite simple, with a zonally oriented dipole having convergence and divergence over the domain that is displaced eastward as the MJO shifts to higher phase numbers. The sequence of pairs in Fig. 6 is roughly in quadrature: a given pair has extrema generally shifted halfway across the domain and lying between the extrema of the immediately preceding pair. Thereby, the 6-7
(8-1) pair has a VP anomaly roughly opposite to the 2-3 (4-5) pair.

The convergence-over-divergence vertical structure after each MJO phase pair (Fig. 6) is compared with the VP fields during heat wave events (Fig. 5). Figure 5 has elements of MJO phase-pair 2-3 (Figs. 6a and e) over the Indian Ocean and Indonesia. Further east, Fig. 5 has elements of 8-1 (Figs. 6d and h) over the central Pacific to Mexico. Only 2-3 and 8-1 in Fig. 6 match the VP over the western United States. These roughly opposite signs and the matching elements are supported by pattern correlation coefficients of the VP fields. The pattern correlations at the two levels are $0.43(0.43),-0.95$ $(-0.92),-0.45(-0.39)$ and $0.90(0.81)$ at $200 \mathrm{hPa}(850 \mathrm{hPa})$ for the 2-3, 4-5, 6-7 and 8-1 phase pairs, respectively.

The "regional" VP field over the CCV after each MJO pair is examined next. After phase-pair 2-3, the CCV has VP $>0$ aloft and $\mathrm{VP}<0$ below, and the part at the CCV is the northern part of strong VP anomalies over the eastern Pacific. After phase-pair 8-1, the CCV also has VP $>0$ aloft and VP $<0$ below at the $\mathrm{CCV}$ - anomalies that are inside the eastern edge of strong VP anomalies over the central Pacific. Over the northeastern Pacific, the 8-1 VP anomaly LSMP declines rapidly from west to east (at $200 \mathrm{hPa}$ ), while the corresponding 2-3 LSMP increases with longitude (Figs. 6a and e). Similarly, at $850 \mathrm{hPa}$, the 2-3 LSMP declines from west to east across the northeastern Pacific, while the 8-1 LSMP increases with longitude (Figs. 6d and h). So, it is not unreasonable to deduce that some combinations of these fields can create midPacific and western United States VP extrema, similar to that found in Fig. 5. After either of those two phase pairs, the shapes of these significant VP anomalies imply convergence over divergence at the $\mathrm{CCV}$, in turn implying sinking that would be favorable to heat wave activation. Unlike Fig. 5, 
2-3
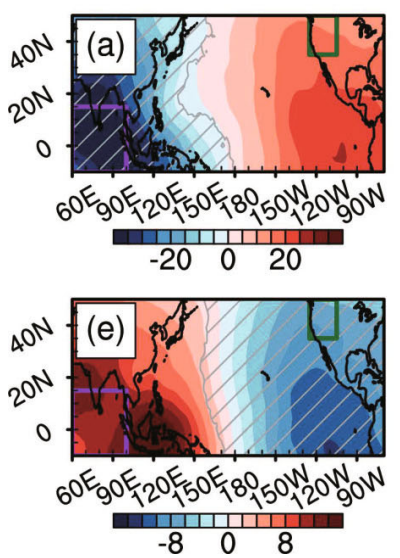

4-5
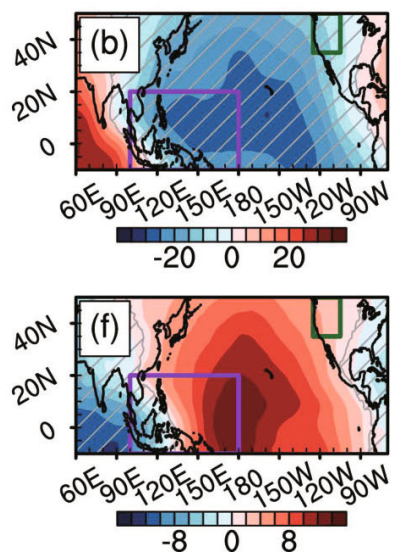

6-7
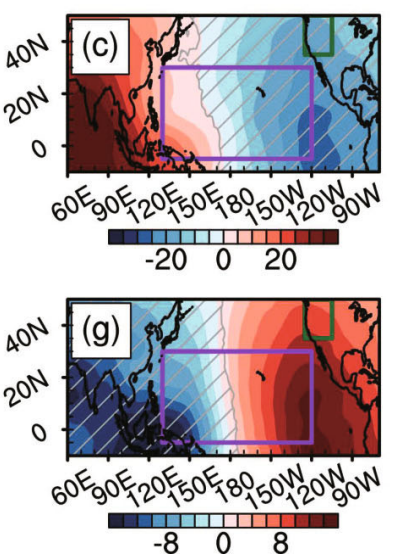

8-1
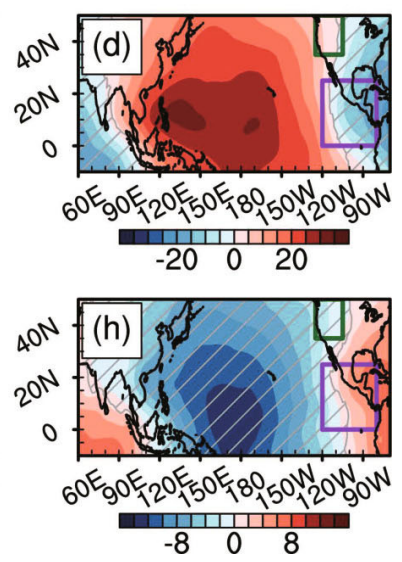

Fig. 6. VP anomaly composites of 4-16 days after all MJO events' onset dates for four phase pairs at (a, b, c, d) 200 hPa and (e, $\mathrm{f}, \mathrm{g}, \mathrm{h}) 850 \mathrm{hPa}$. The units for the shading are $10^{5} \mathrm{~m}^{2} \mathrm{~s}^{-1}$. Hatched areas enclosed with contours are significant at the $95 \%$ confidence level according to the two-tailed Student's $t$-test. Purple boxes show areas of larger OLR magnitude in corresponding phase pairs (as in Fig. 1).

neither phase pair has a separate VP extremum there. The VP anomaly signal over the CCV is consistent, judged by exceeding a $1 / 3$ sign-fraction value only after phase-pairs 2-3 and 6-7, but not 4-5 and 8-1 (Fig. S2 in the ESM). Thus, the convergence-over-divergence structure may be less robust in phase-pair 8-1 compared to phase-pair 2-3.

Both the larger similarity of VP LSMP and strong $\mathrm{CCV}$ area convergence-over-divergence structure support the strong association between MJO and CCV heat waves. Phase-pair 2-3 shows significant and consistent positive anomalies aloft and negative anomalies below in western North America, and the large-scale VP pattern is similar to the field of heat waves in the tropical Indian Ocean pattern. After phase-pair 8-1 MJO, the central Pacific VP lobe is quite similar to the heat waves, and significant CCV area anomalies are observed, although they are less consistent than phasepair 2-3 MJO. These results indicate that both phase pairs (2-3 and 8-1) of the MJO have a connection to the CCV heat waves. However, after phase-pairs 4-5 and 6-7, the largescale VP pattern is reversed from the VP field during CCV heat waves. Pairs 4-5 and 6-7 imply rising motion that is obviously unfavorable for adiabatic heating of air parcels, but is consistent with the cooler temperatures and smaller fraction of hot days shown in Fig. 3.

\section{Distinct MJO associations between two types of CCV heat waves}

Prior work (Lee and Grotjahn, 2016) identified two different types of CCV heat waves based on their spatial and temporal development. Lee and Grotjahn (2016) showed that one type of heat wave (labelled "Cluster 1") tends to form a strong lower-tropospheric hot-temperature anomaly over a region centered just offshore of the northwest California and southwest Oregon coasts only immediately before on- set, with cold anomalies prevailing off the northwest United States coast several days before. A second type of CCV heat wave (labelled "Cluster 2") develops hot temperatures in that same offshore region but as a southwestward extension of a hot anomaly covering southwestern Canada that exists several days prior to the onset of CCV heat waves. Prior sections of this article consider all heat wave events at once. This section considers each cluster of heat wave events separately and executes parallel analyses of MJO associations for each heat wave cluster. During the 1979-2010 period used here, there are 11 events in Cluster 1 and 9 events in Cluster 2. The remaining four events are a mixture of both cluster types.

OLR anomaly composites over the first three days of all heat waves (i.e., including the onset date plus the next two dates) are shown in Fig. 7. These composites clearly show significant positive anomalies over the CCV extending to the offshore region in both clusters. However, the strength and spatial coverage differs between the two clusters. In Cluster 1 , strong OLR $>0$ dominates over most of western North America, while this anomaly is shifted to the north and higher anomalies are relatively confined to the coast in Cluster 2. The distribution of negative OLR anomalies over North America is distinct in the two clusters. In Cluster 1, negative anomalies are mainly located in Mexico, Texas, and the Midwest. In Cluster 2, however, they are situated further south from offshore of southwestern Mexico across the Gulf of Mexico and extending along the United States east coast. The pairing of negative (ascending) anomalies to the south and positive (descending) anomalies to the north suggests that the Matsuno-Gill model may be applicable at least during days after the onset of heat wave events in both clusters, as mentioned before. However, the enhanced convection (implied by the OLR anomalies) in Cluster 1 is mostly over the land surface and not over the eastern Pacific Ocean surface, while much of the Cluster 2 OLR $<0$ LSMP is over water. The meridional scale of a circulation from southern convection to 


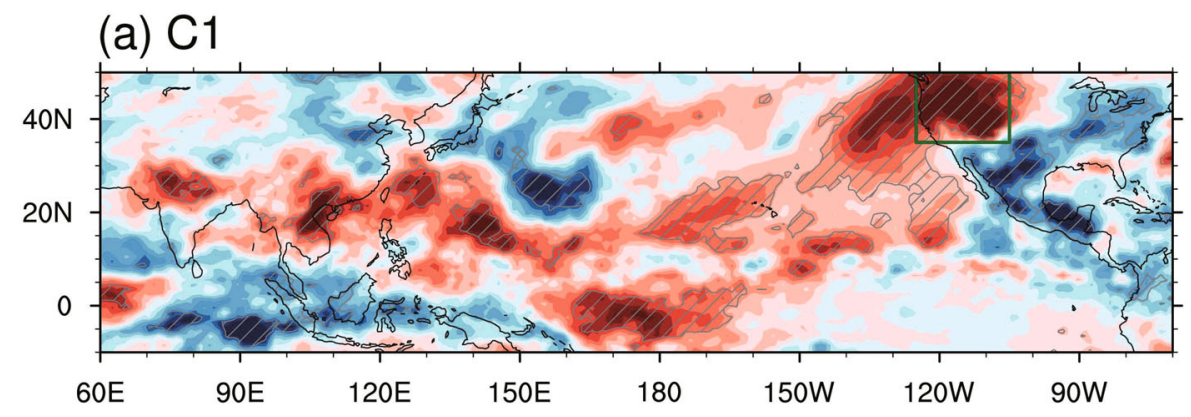

(b) $\mathrm{C} 2$

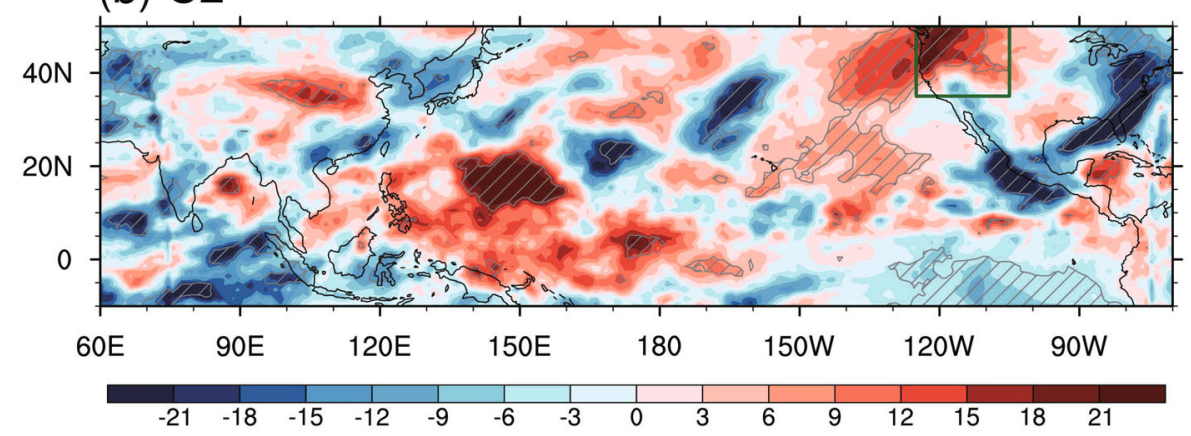

Fig. 7. OLR anomaly composites over the first three days of CCV heat wave events for (a) Custer 1 and (b) Cluster 2. The units for the shading are $\mathrm{W} \mathrm{m}^{-2}$. Hatched areas enclosed with contours are significant at the $95 \%$ confidence level according to the two-tailed Student's $t$-test.

north-northwest subsidence is smaller in Cluster 1 compared to Cluster 2.

The VP anomaly composites over the first three days of all heat waves are displayed for each of the two heat wave clusters and compared for upper- and lower-tropospheric levels in Fig. 8. Cluster 1 shows very clear and significant patterns of negative anomalies to the west (tropical Indian Ocean) and positive anomalies to the east (central North Pacific) at $200 \mathrm{hPa}$, with the pattern largely reversing sign at 850 hPa (Figs. 8a and b). The Cluster 1 pattern visually matches the MJO phase-pair 8-1 composite pattern (Fig. 6) better than other phase pairs. The Cluster 2 VP anomaly composites at $200 \mathrm{hPa}$ are weaker than in Cluster 1 in both positive and negative anomaly cells, while negative anomalies at $850 \mathrm{hPa}$ are stronger than in Cluster 1 . In addition, the positive anomaly cell aloft and negative anomaly cell below are displaced to the western Pacific. The pattern of Cluster 2 looks generally similar to the MJO phase-pair 8-1 composite pattern (Figs. 6d and h), but less similar than Cluster 1 does.

The details near the CCV for the two clusters are noteworthy. Cluster 1 has a significant, localized, strong VP $>0$ anomaly over strong VP $<0$ anomaly over western North America. In Cluster 2, however, the VP vertical structure is weak and insignificant there. Close inspection of Cluster 2 reveals at the $850 \mathrm{hPa}$ level a significant VP minimum off the British Columbia and Washington coast and a VP ridge centered to the southeast, extending to Mexico. The pattern for Cluster 2 in Fig. 8e implies sinking off the British Columbia and Washington coasts that is consistent with the OLR fields during heat wave onset (Fig. 7b), as well as the pre-existing heat wave in southwestern Canada at the time of Cluster 2 heat wave onset [shown in Lee and Grotjahn (2016)].

The MJO phase-pair associations with the two heat wave clusters is quantitatively assessed using pattern correlations of VP fields (Figs. 8c and f). Both the Cluster 1 and 2 composites show the largest pattern correlations with phase-pair 8-1, consistent with the description above. A major difference between the two clusters is that in Cluster 2 the correlations for all four phase pairs are smaller in magnitude than corresponding correlations in Cluster 1. Notably, the pattern correlation for phase-pair 2-3 is negligibly small for Cluster 2 but not for Cluster 1. The pattern of VP, especially the westward-shifted North Pacific anomalies, is out of phase with the pattern of the 2-3 phase pairs; therefore, the correlation for the 2-3 pair field is much less with Cluster 2. From the results in Figs. 7 and 8 , it is deduced that Cluster $2 \mathrm{CCV}$ heat waves are less well associated with leading MJO convections but, to the extent they are associated, they are more linked to phase-pair 8-1 (eastern Pacific) convection than other phase pairs.

\section{Discussion and summary}

In prior works (Grotjahn and Faure, 2008; Grotjahn, 2011; Lee and Grotjahn, 2016), LSMPs in the subtropical, middle, and high latitudes were identified that are associated with CCV heat waves. This study explores the tropical MJO connection to CCV heat waves by comparing LSMPs during the heat waves and after the MJO convection. The associations are tracked for different longitudinal locations of 
C1
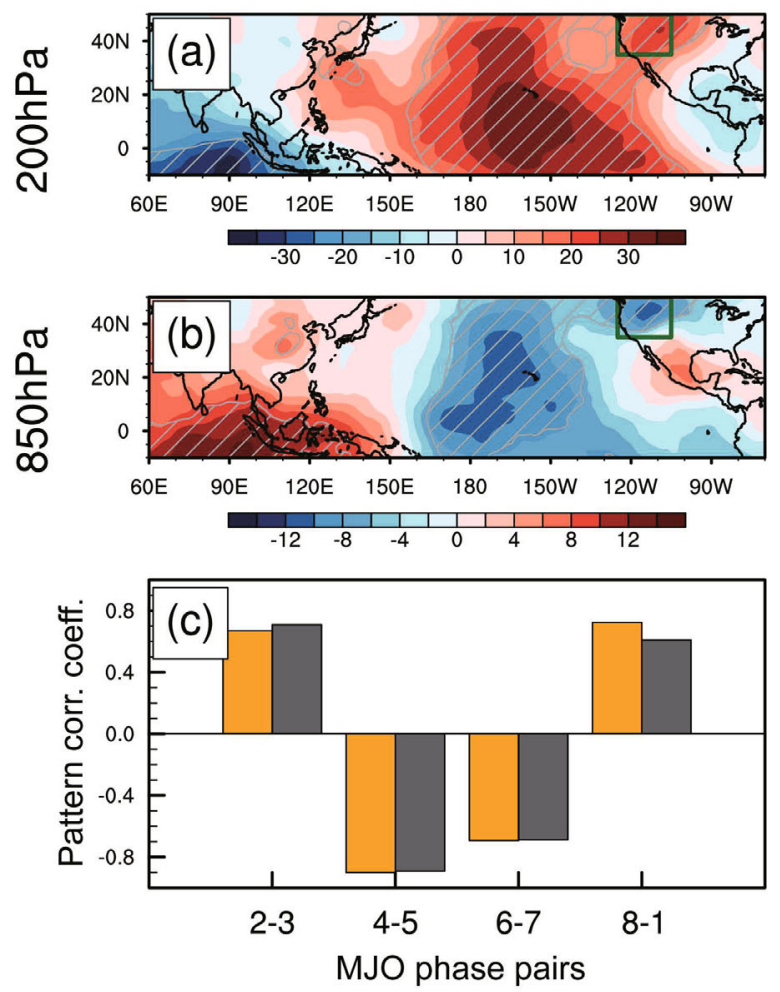

C2
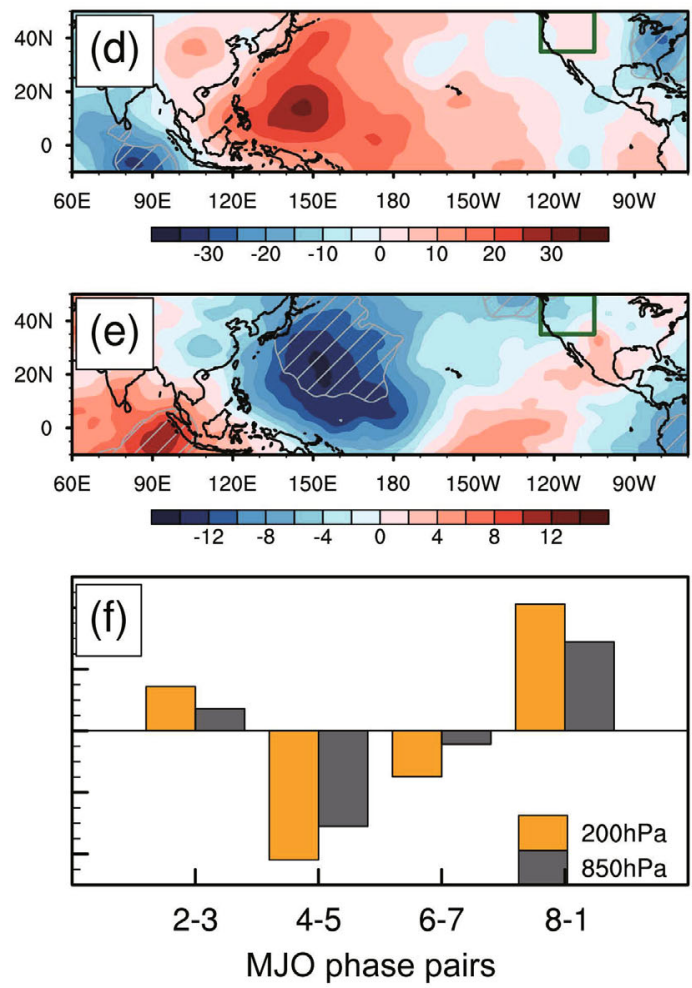

Fig. 8. VP anomaly composites over the first three days of CCV heat wave events-similar to Fig. 5, but for each of two clusters at (a, d) $200 \mathrm{hPa}$ and (b, e) $850 \mathrm{hPa}$. The units for the shading are $10^{5} \mathrm{~m}^{2} \mathrm{~s}^{-1}$. Hatched areas enclosed with contours are significant at the $95 \%$ confidence level according to the two-tailed Student's $t$-test. Bars in (c, f) show pattern correlation coefficients between the individual VP fields of two CCV heat wave clusters (a, b, d, e) and the VP field during 4-16 days after MJO events for each of four phase pairs (shown in Fig. 6) over the whole domain $\left(10^{\circ} \mathrm{S}-50^{\circ} \mathrm{N}, 60^{\circ} \mathrm{E}-70^{\circ} \mathrm{W}\right)$. Orange and dark gray bars are for $200 \mathrm{hPa}$ and $850 \mathrm{hPa}$, respectively.

the tropical convection in terms of MJO RMM index phase pairs. The MJO in summertime is characterized not only by eastward migration of a region of tropical convection, but also by northward propagation and expansion of the convective region as it approaches the eastern Pacific-a pattern that is generally seen from OLR anomaly composites. OLR anomaly composites prior to CCV heat waves look like a combination of the Indian Ocean (MJO 2-3 phase pair) and the eastern Pacific (MJO 8-1 phase pair) convection patterns (Fig. 2). In addition, those two phase pairs are more frequently active prior to heat waves compared to the other two phase pairs. The fact that the CCV heat waves are preceded by specific phases of MJO convection prompted this research.

One would not expect distant tropical convection to immediately affect the CCV. The average time taken to affect the CCV is estimated from time series of the mean normalized temperature anomalies at $\mathrm{CCV}$ stations and the fraction of 5\% hot days after the onset of each MJO event (Fig. 3). Those two temperature metrics show that the timing of hot weather after $\mathrm{MJO}$ events differs among the four phase pairs: earlier activation and sooner decay for phase-pair 8-1; later activation for phase-pair 2-3. Also evident is the activation of the cooler temperatures for phase-pairs 4-5 and 6-7. By synthesizing the results of two temperature-extreme metrics, the time periods of 4 to 16 days after the onset of MJO events was chosen. Two temperature-extreme metrics averaged during that time period indicate that $\mathrm{CCV}$ heat waves are the most strongly connected to eastern Pacific MJO convection (phase-pair 8-1), and secondarily connected to Indian Ocean MJO convection (phase-pair 2-3). Heat waves are least connected to Maritime Continent MJO convection (phase-pair 4$5)$.

The LSMP of OLR after 4 to 16 days after the onset of MJO events (Fig. 4) clearly displays an eastward and northward displaced pattern of the typical summertime MJO convection for four individual phase pairs. OLR is used as a proxy for vertical motions. In far distant, extratropical, western North America, apparent subsidence is detected only after phase-pairs 2-3 and 8-1 and not after phase-pairs 4-5 and 6-7.

VP anomaly fields after MJO phase pairs are examined on two pressure levels $(200 \mathrm{hPa}$ and $850 \mathrm{hPa}$ ) in association with CCV heat waves. The Laplacian of VP is the divergence, so VP anomalies could be interpreted in terms of general areas of divergence $(\mathrm{VP}<0)$ and convergence $(\mathrm{VP}>0)$. VP sign reversal with height occurs in areas of enhanced upward 
or downward motion anomalies. As expected, a localized convergence-over-divergence structure occurs over the western United States during three-day periods beginning with the onset of each heat wave. The LSMP of the VP anomaly at both levels shows clear zonal asymmetry with divergence over convergence to the west (tropical Indian Ocean) and convergence over divergence to the east of approximately $120^{\circ} \mathrm{E}$ (western to central North Pacific) (Fig. 5). When compared to this pattern, VP anomaly fields after MJO phase-pairs 2-3 and 8-1 (Fig. 6) each match specific parts. In addition, part of the VP LSMP extending to the eastern North Pacific after these two phase pairs is conducive to the formation of CCV heat waves, with enhanced convergence over divergence there. These MJO lagged composites indicate robust associations between CCV heat waves and specific MJO phases and are consistent with the MJO phase dependencies deduced from extreme-temperature metrics; the CCV hot weather is most common after the eastern Pacific MJO, and next most common after Indian Ocean MJO phases.

The MJO connections to the two types of CCV heat waves are examined by making parallel comparisons to those done for all heat waves. Both clusters have strong subsidence in the eastern North Pacific paired with significant enhanced convection to the south-southeast. Cooler temperatures and higher sea level pressure off the Californian coast have been linked to increased OLR values in Central America and across the equator (Grotjahn and Osman, 2007), as well as opposite signs for these features. However, the pattern appears to be a stronger Matsuno-Gill model response in Cluster 2 than Cluster 1. VP anomalies at zero to two days after $\mathrm{CCV}$ heat wave onset reveal additional differences between the two cluster types. One notable difference occurs over the CCV: much weaker magnitude of the VP anomaly in Cluster 2 compared to Cluster 1, implying upper-level convergence and lower-level divergence in-situ is less prominent during Cluster 2 heat waves. Another difference is the convergenceover-divergence structure over the Pacific is shifted far westward for Cluster 2. Consequently, the LSMP has less consistency with VP fields formed from lagging MJO phase pairs, except phase-pair 8-1. Therefore, Cluster 2 has less association with the MJO and is only evident after phase-pair 8-1.

The midlatitude Rossby wave source is usually strong at the polar side of tropical convection, leading to upper-level extratropical convergence that then generates transient waves that propagate eastward (Tyrrell et al., 1996). Individual VP anomaly fields show that an eastward-propagating wave signal is usually present before heat wave onset in both clusters (not shown). This may be partly associated with MJOs, although in the anomaly pattern it is hard to isolate solely a tropics-originated signal from intrinsic subtropical transient waves. A wavy pattern in extratropical VP fields is more clearly visible in Cluster 1 than in Cluster 2, with shorter wavelength in Cluster 1 (Fig. 8). These features are consistent with geopotential height composite fields shown in Lee and Grotjahn (2016).

It is challenging to isolate clearly the contributions of tropical convection in different longitudinal locations (that is, the contribution of different MJO phases) to phenomena in a remote subtropical region. For instance, CCV hot-weather activity after MJO phase-pair 2-3 could be partly contaminated by other subsequent phase pairs given the distance between the atmospheric phenomena. However, this study mitigates that interference by focusing upon substantially strong MJO events. In conclusion, this study has found statistically significant connections between specific MJO phases and CCV heat waves, and those connections should motivate further modeling and observational studies to explore the dynamical connections.

Acknowledgements. This research was funded in part by the NSF (Grant No. 1236681), NASA (Grant No. NNX16AG62G), the Department of Energy Office of Science (Award No. DESC0016605), and the USDA National Institute of Food and Agriculture, Hatch project Accession \#1010971. This research was also supported by the Asia-Pacific Economic Cooperation Climate Center in the Republic of Korea.

Electronic supplementary material. Supplementary material is available in the online version of this article at https://doi.org/ 10.1007/s00376-019-8167-1.

Open Access This article is distributed under the terms of the Creative Commons Attribution License which permits any use, distribution, and reproduction in any medium, provided the original author(s) and the source are credited.

\section{REFERENCES}

Alexander, L. V., P. Uotila, and N. Nicholls, 2009: Influence of sea surface temperature variability on global temperature and precipitation extremes. J. Geophys. Res.: Atmos. 114, D18116, https://doi.org/10.1029/2009JD012301.

Brown, S. J., J. Caesar, and C. A. T. Ferro, 2008: Global changes in extreme daily temperature since 1950. J. Geophys. Res.: Atmos 113, D05115, https://doi.org/10.1029/2006JD008091.

Cellitti, M. P., J. E. Walsh, R. M. Rauber, and D. H. Portis, 2006: Extreme cold air outbreaks over the United States, the polar vortex, and the large-scale circulation. J. Geophys. Res.: Atmos., 111, D02114, https://doi.org/10.1029/2005JD006273.

Dee, D. P., and Coauthors , 2011: The ERA-Interim reanalysis: Configuration and performance of the data assimilation system. Quart. J. Roy. Meteor. Soc., 137, 553-597, https://doi. org/10.1002/qj.828.

Downton, M. W., and K. A. Miller, 1993: The freeze risk to Florida citrus. Part II: Temperature variability and circulation patterns. J. Climate, 6, 364-372, https://doi.org/10.1175/15200442(1993)006<0364:TFRTFC >2.0.CO;2.

Gershunov, A., D. R. Cayan, and S. F. Iacobellis, 2009: The great 2006 heat wave over California and Nevada: Signal of an increasing trend. J. Climate, 22, 6181-6203, https://doi.org/ 10.1175/2009JCLI2465.1.

Gill, A. E., 1980: Some simple solutions for heat-induced tropical circulation. Quart. J. Roy. Meteor. Soc., 106, 447-462, https:// doi.org/10.1002/qj.49710644905.

Grotjahn, R., 2011: Identifying extreme hottest days from large scale upper air data: A pilot scheme to find California Cen- 
tral Valley summertime maximum surface temperatures. Climate Dyn., 37, 587-604, https://doi.org/10.1007/s00382-0110999-z.

Grotjahn, R., 2013: Ability of CCSM4 to simulate California extreme heat conditions from evaluating simulations of the associated large scale upper air pattern. Climate Dyn., 41, 11871197, https://doi.org/10.1007/s00382-013-1668-1.

Grotjahn, R., 2016: Western North American extreme heat, associated large scale synoptic-dynamics, and performance by a climate model. Dynamics and Predictability of Large-Scale High-Impact Weather and Climate Events, J. P. Li et al., Eds., Cambridge University Press, Cambridge. 198-209.

Grotjahn, R., and M. Osman, 2007: Remote weather associated with North Pacific subtropical sea level high properties. International Journal of Climatology, 27, 587-602, https://doi.org/ 10.1002/joc. 1423 .

Grotjahn, R., and G. Faure, 2008: Composite predictor maps of extraordinary weather events in the Sacramento, California, Region. Wea. Forecasting, 23, 313-335, https://doi.org/10.1175/ 2007WAF2006055.1.

Grotjahn, R., and Coauthors, 2016: North American extreme temperature events and related large scale meteorological patterns: A review of statistical methods, dynamics, modeling, and trends. Climate Dyn., 46, 1151-1184, https://doi.org/ 10.1007/s00382-015-2638-6.

Guirguis, K., A. Gershunov, R. Schwartz, and S. Bennett, 2011: Recent warm and cold daily winter temperature extremes in the Northern Hemisphere. Geophys. Res. Lett., 38, L17701, https://doi.org/10.1029/2011GL048762.

Higgins, R. W., and K. C. Mo, 1997: Persistent North Pacific circulation anomalies and the tropical intraseasonal oscillation. J. Climate, 10, 223-244, https://doi.org/10.1175/1520-0442 (1997)010<0223:PNPCAA>2.0.CO;2.

Higgins, R. W., A. Leetmaa, and V. E. Kousky, 2002: Relationships between climate variability and winter temperature extremes in the United States. J. Climate, 15, 1555-1572, https:// doi.org/10.1175/1520-0442(2002)015<1555:RBCVAW>2.0. $\mathrm{CO} ; 2$.

Hong, C.-C., and T. Li, 2009: The extreme cold anomaly over Southeast Asia in february 2008: Roles of ISO and ENSO. J. Climate, 22, 3786-3801, https://doi.org/10.1175/2009JCLI 2864.1.

Hoskins, B. J., 1996: On the existence and strength of the summer subtropical anticyclones. Bernhard Haurwitz memorial lecture. Bull. Amer. Meteorol. Soc., 77, 1287-1292.

Hoskins, B., R. Neale, M. Rodwell, and G.-Y. Yang, 1999: Aspects of the large-scale tropical atmospheric circulation. Tellus $B$, 51, 33-44, https://doi.org/10.3402/tellusb.v51i1.16258.

Jeong, J.-H., C.-H. Ho, B.-M. Kim, and W.-T. Kwon, 2005: Influence of the Madden-Julian Oscillation on wintertime surface air temperature and cold surges in East Asia. J. Geophys. Res: Atmos., 110, D11104, https://doi.org/10.1029/2004JD005408.

Jeong, J.-H., B.-M. Kim, C.-H. Ho, and Y.-H. Noh, 2008: Systematic variation in wintertime precipitation in East Asia by MJO-induced extratropical vertical motion. J. Climate, 21, 788-801, https://doi.org/10.1175/2007JCLI1801.1.

Jin, F. F., and B. J. Hoskins, 1995: The direct response to tropical heating in a baroclinic atmosphere. J. Atmos. Sci., 52, 307-319, https://doi.org/10.1175/1520-0469(1995)052 $<0307$ :TDRTTH $>2.0$. CO; 2 .

Jones, C., J. Gottschalck, L. M. V. Carvalho, and W. Higgins,
2011: Influence of the Madden-Julian Oscillation on forecasts of extreme precipitation in the contiguous United States. Mon. Wea. Rev., 139, 332-350, https://doi.org/10.1175/2010 MWR3512.1.

Kenyon, J., and G. C. Hegerl, 2008: Influence of modes of climate variability on global temperature extremes. J. Climate, 21, 3872-3889, https://doi.org/10.1175/2008JCLI2125.1.

Kiladis, G. N., and K. M. Weickmann, 1992: Circulation anomalies associated with tropical convection during northern winter. Mon. Wea. Rev., 120, 1900-1923, https://doi.org/10.1175/ 1520-0493(1992)120<1900:CAAWTC > 2.0.CO;2.

Kiladis, G. N., J. Dias, K. H. Straub, M. C. Wheeler, S. N. Tulich, K. Kikuchi, K. M. Weickmann, and M. J. Ventrice, 2014: A Comparison of OLR and circulation-based indices for tracking the MJO. Mon. Wea. Rev., 142, 1697-1715, https://doi.org/10.1175/MWR-D-13-00301.1.

Lau, K.-M., and T. J. Phillips, 1986: Coherent fluctuations of fxtratropical geopotential height and tropical convection in intraseasonal time scales. J. Atmos. Sci., 43, 1164-1181, https:// doi.org/10.1175/1520-0469(1986) 043<1164:CFOFGH >2.0. $\mathrm{CO} ; 2$.

Lee, H.-T., A. Gruber, R. G. Ellingson, and I. Laszlo, 2007: Development of the HIRS outgoing longwave radiation climate dataset. J. Atmos. Oceanic Technol., 24, 2029-2047, https:// doi.org/10.1175/2007JTECHA989.1.

Lee, Y.-Y., and R. X. Black, 2013: Boreal winter low-frequency variability in CMIP5 models. J. Geophys. Res.: Atmos. 118, 6891-6904, https://doi.org/10.1002/jgrd.50493.

Lee, Y.-Y., and R. Grotjahn, 2016: California central valley summer heat waves form two ways. J. Climate, 29, 1201-1217, https://doi.org/10.1175/JCLI-D-15-0270.1.

Lim, Y.-K., and S. D. Schubert, 2011: The impact of ENSO and the Arctic Oscillation on winter temperature extremes in the southeast United States. Geophys. Res. Lett., 38, L15706, https://doi.org/10.1029/2011GL048283.

Lin, H., and G. Brunet, 2009: The influence of the Madden-Julian oscillation on Canadian wintertime surface air temperature. Mon. Wea. Rev., 137, 2250-2262, https://doi.org/10.1175/ 2009MWR2831.1.

Lin, H., G. Brunet, and J. Derome, 2009: An observed connection between the North Atlantic oscillation and the MaddenJulian Oscillation. J. Climate, 22, 364-380, https://doi.org/ 10.1175/2008JCLI2515.1.

Lin, H., G. Brunet, and R. P. Mo, 2010: Impact of the MaddenJulian oscillation on wintertime precipitation in Canada. Mon. Wea. Rev., 138, 3822-3839, https://doi.org/10.1175/2010 MWR3363.1.

Loikith, P. C., and A. J. Broccoli, 2014: The influence of recurrent modes of climate variability on the occurrence of winter and summer extreme temperatures over North America. $J$. Climate, 27, 1600-1618, https://doi.org/10.1175/JCLI-D-1300068.1.

Madden, R. A., and P. R. Julian, 1972: Description of global-scale circulation cells in the tropics with a $40-50$ day period. $J$. Atmos. Sci., 29, 1109-1123, https://doi.org/10.1175/1520-0469 (1972)029<1109:DOGSCC >2.0.CO;2.

Madden, R. A., and P. R. Julian, 1994: Observations of the 40-50-day tropical oscillation-A review. Mon. Wea. Rev., 122, 814-837, https://doi.org/10.1175/1520-0493(1994)122 $<0814$ :OOTDTO $>2.0 . \mathrm{CO} ; 2$.

Matsueda, S., and Y. Takaya, 2015: The global influence of the Madden-Julian oscillation on extreme temperature events. $J$. 
Climate, 28, 4141-4151, https://doi.org/10.1175/JCLI-D-1400625.1 .

Matsuno, T., 1966: Quasi-geostrophic motions in the equatorial area. J. Meteorol. Soc. Japan Ser. II, 44, 25-43, https:// doi.org/10.2151/jmsj1965.44.1_25.

Matthews, A. J., B. J. Hoskins, and M. Masutani, 2004: The global response to tropical heating in the Madden-Julian oscillation during the northern winter. Quart. J. Roy. Meteorol. Soc., 130, 1991-2011, https://doi.org/10.1256/qj.02.123.

Meehl, G. A., and H. Y. Teng, 2007: Multi-model changes in El Niño teleconnections over North America in a future warmer climate. Climate Dyn., 29, 779-790, https://doi.org/10.1007/ s00382-007-0268-3.

Moon, J.-Y., B. Wang, and K.-J. Ha, 2011: ENSO regulation of MJO teleconnection. Climate Dyn., 37, 1133-1149, https:// doi.org/10.1007/s00382-010-0902-3.

Mori, M., and M. Watanabe, 2008: The growth and triggering mechanisms of the PNA: A MJO-PNA coherence. J. Meteorol. Soc. Japan Ser. II, 86, 213-236, https://doi.org/10.2151/ jmsj.86.213.

Palipane, E., and R. Grotjahn, 2018: Future projections of the large-scale meteorology associated with California heat waves in CMIP5 models. J. Geophys. Res.: Atmos. 123, 8500-8517, https://doi.org/10.1029/2018JD029000.

Schreck, C. J., J. M. Cordeira, and D. Margolin, 2013: Which MJO events affect North American temperatures? Mon. Wea. Rev., 141, 3840-3850, https://doi.org/10.1175/MWR-D-1300118.1.

Sillmann, J., M. Croci-Maspoli, M. Kallache, and R. W. Katz, 2011: Extreme cold winter temperatures in Europe under the influence of North Atlantic atmospheric blocking. J. Climate, 24, 5899-5913, https://doi.org/10.1175/2011JCLI4075.1.

Tyrrell, G. C., D. J. Karoly, and J. L. McBride, 1996: Links between tropical convection and variations of the extratropical circulation during TOGA COARE. J. Atmos. Sci., 53, 2735-2748, https://doi.org/10.1175/1520-0469(1996)053 $<2735$ :LBTCAV > 2.0.CO;2.

Walsh, J. E., A. S. Phillips, D. H. Portis, and W. L. Chapman, 2001: Extreme cold outbreaks in the United States and Europe, 1948-99. J. Climate, 14, 2642-2658, https://doi.org/10.1175/ 1520-0442(2001)014<2642:ECOITU>2.0.CO;2.

Wang, S. G., D. Ma, A. H. Sobel, and M. K. Tippett, 2018: Propagation characteristics of BSISO indices. Geophys. Res. Lett. 45(18), 9934-9943, https://doi.org/10.1029/2018GL078321.

Wettstein, J. J., and L. O. Mearns, 2002: The influence of the North Atlantic-Arctic Oscillation on mean, variance, and extremes of temperature in the Northeastern United States and Canada. J. Climate, 15, 3586-3600, https://doi.org/10.1175/15200442(2002)015<3586:TIOTNA>2.0.CO;2.

Wheeler, M. C., and H. H. Hendon, 2004: An all-season realtime multivariate MJO index: Development of an index for monitoring and prediction. Mon. Wea. Rev., 132, 19171932, https:// doi.org/10.1175/1520-0493 (2004) 132<1917: AARMMI $>2.0 . \mathrm{CO} ; 2$.

Wheeler, M. C., H. H. Hendon, S. Cleland, H. Meinke, and A. Donald, 2009: Impacts of the Madden-Julian oscillation on Australian rainfall and circulation. J. Climate, 22, 1482-1498, https://doi.org/10.1175/2008JCLI2595.1.

Zhang, C. D., 2005: Madden-julian oscillation. Rev. Geophys., 43, RG2003, https://doi.org/10.1029/2004RG000158.

Zhou, S. T., M. L'Heureux, S. Weaver, and A. Kumar, 2012: A composite study of the MJO influence on the surface air temperature and precipitation over the continental United States. Climate Dyn., 38, 1459-1471, https://doi.org/10.1007/ s00382-011-1001-9. 